\title{
Effect of Insulin on the Distribution and Disposition of Glucose in Man
}

Eleuterio Ferrannini, J. Douglas Smith, Claudio Cobelli, Gianna Toffolo, Alessandro Pilo, and Ralph A. DeFronzo Second Medical Clinic and Institute of Clinical Physiology of the Consiglio Nazionale delle Ricerche, University of Pisa, Pisa, Italy; Department of Electrical Engineering, University of Padova, Padova, Italy; and Department of Medicine, Yale University School of Medicine, New Haven, Connecticut 06510

\section{Abstract}

Understanding the influence of insulin on glucose turnover is the key to interpreting a great number of metabolic situations. Little is known, however, about insulin's effect on the distribution and exchange of glucose in body pools. We developed a physiological compartmental model to describe the kinetics of plasma glucose in normal man in the basal state and under steady-state conditions of euglycemic hyperinsulinemia.

A bolus of $\left[3^{-3} \mathbf{H}\right]$ glucose was rapidly injected into a peripheral vein in six healthy volunteers, and the time-course of plasma radioactivity was monitored at very short time intervals for $150 \mathrm{~min}$. A $1-\mathrm{mU} / \mathrm{min} \mathrm{kg}$ insulin clamp was then started, thereby raising plasma insulin levels to a high physiological plateau $(\sim 100 \mu \mathrm{U} / \mathrm{ml})$. After $90 \mathrm{~min}$ of stable euglycemic hyperinsulinemia, a second bolus of $\left[3-{ }^{3} \mathrm{H}\right]$ glucose was given, and plasma radioactivity was again sampled frequently for $\mathbf{9 0}$ min more while the clamp was continued.

Three exponential components were clearly identified in the plasma disappearance curves of tracer glucose of each subject studied, both before and after insulin. Based on stringent statistical criteria, the data in the basal state were fitted to a three-compartment model. The compartment of initial distribution was identical to the plasma pool $(40 \pm 3 \mathrm{mg} / \mathrm{kg})$; the other two compartments had similar size $(91 \pm 12$ and $96 \pm 9$ $\mathrm{mg} / \mathrm{kg}$ ), but the former was in rapid exchange with plasma (at an average rate of $1.09 \pm 0.15 \mathrm{~min}^{-1}$ ), whereas the latter exchanged 10 times more slowly $\left(0.12 \pm 0.01 \mathrm{~min}^{-1}\right)$. The basal rate of glucose turnover averaged $2.15 \pm 0.12 \mathrm{mg} / \mathrm{min} \mathrm{kg}$, and the total distribution volume of glucose in the postabsorptive state was $26 \pm 1 \%$ of body weight. In view of current physiological information, it was assumed that the more rapidly exchanging pool represented the insulin-independent tissues of the body, while the slowly exchanging pool was assimilated to the insulin-dependent tissues. Insulin-independent glucose uptake was estimated (from published data) at $75 \%$ of basal glucose uptake, and was constrained not to change with euglycemic hyperinsulinemia. When the kinetic data obtained during insulin administration were fitted to this model, neither the size nor the exchange rates of the plasma or the rapid pool were appreciably changed. In contrast, the slow pool was markedly expanded (from $96 \pm 9$ to $190 \pm 30 \mathrm{mg} / \mathrm{kg}, P<0.02$ ) at the same time as total glucose disposal rose fourfold above basal (to

Address correspondence to Dr. Ferrannini, C.N.R. Institute of Clinical Physiology, Via Savi, 8, 56100 Pisa, Italy. 1985.

Received for publication 7 March 1984 and in revised form 6 March

J. Clin. Invest.

(c) The American Society for Clinical Investigation, Inc.

0021-9738/85/07/0357/08 \$1.00

Volume 76, July 1985, 357-364
$7.96 \pm 0.85 \mathrm{mg} / \mathrm{min} \mathrm{kg}, P<0.001)$. Furthermore, a significant direct correlation was found to exist between the change in size of the slow pool and the insulin-stimulated rate of total glucose turnover $(r=0.92, P<0.01)$.

We conclude that hyperinsulinemia, independent of hyperglycemia, markedly increases the exchangeable mass of glucose in the body, presumably reflecting the accumulation of free, intracellular glucose in insulin-dependent tissues.

\section{Introduction}

Information concerning the rate of glucose turnover is important in a number of physiological and clinical circumstances. Glucose tracers are therefore used yet more frequently to measure the rate of glucose appearance in the peripheral circulation and its rate of removal from the plasma simultaneously. Insulin has profound effects on endogenous glucose release and glucose uptake by sensitive tissues. Little is known, however, about the influence of insulin on the distribution volume of body glucose and on the rate of glucose exchange between its various compartments. In vitro studies have shown that insulin enhances the transport of glucose (and other metabolizable sugars) across the cell membrane of muscle cells more than it stimulates the subsequent steps of intracellular glucose disposal. This results in the buildup of free glucose in the cytoplasm (1). Whether this phenomenon occurs in the intact organism to any physiologically meaningful extent is not known. The in vivo estimation of pool sizes from tracer data is dependent upon the assumption of a kinetic model for the substance (2). Many models for the glucose system have been proposed in the past (3-12). Models should evolve, however, as new physiological information is gained and new techniques become available. Glucose disposition by various tissues in vivo has been extensively investigated in recent years (13-17). Furthermore, two important methodological developments have greatly advanced our knowledge of glucose metabolism in vivo: first, the glucose clamp technique (18) has made it possible to interrupt the feedback loop between glucose and insulin; second, glucose tracers that do not undergo large recycling (e.g., $\left[{ }^{3} \mathrm{H}\right]$ glucose) have been introduced (19-22).

The aim of this study, therefore, was to develop a minimumassumption, physiological model of glucose kinetics to be used directly to test the effect of insulin, independent of changes in plasma glucose concentration, on body glucose distribution. We performed paired studies in normal subjects using [3- $\left.{ }^{3} \mathrm{H}\right]$ glucose as the tracer, in the basal state and under conditions closely approximating a steady state of euglycemic hyperinsulinemia (glucose clamp technique). Stringent mathematical criteria and recent physiological data were used to select a compartmental glucose model. The results indicate that insulin leads to the accumulation of free intracellular glucose in man. 


\section{Methods}

Subjects. Six healthy, young volunteers (one woman and five men) participated in the study. Their mean age was $23 \pm 2$ yr (mean \pm SEM); their mean height was $176 \pm 5 \mathrm{~cm}$, and their mean body weight, $72 \pm 6$ $\mathrm{kg}$, corresponding to $1.87 \pm 0.10$ square meters of body surface area and to an obesity index of $1.06 \pm 0.04$ (Metropolitan Life Insurance Co. Tables, Chicago, 1959). The subjects had negative family histories for diabetes mellitus; they had had no recent change in body weight, and no intercurrent illness, and presented no symptoms or signs of liver or kidney disease. They were instructed to consume a weightmaintaining diet containing at least $200 \mathrm{~g}$ carbohydrate per $\mathrm{d}$ for $3 \mathrm{~d}$ before the study. No subjects were taking any medication. The purpose, nature, and potential risks of the study were explained to all subjects, and written consent was obtained from them before their participation. The protocol was reviewed and approved by the Committee on Human Investigation at Yale University School of Medicine, New Haven, CT.

\section{Experimental protocol}

All subjects were studied in the postabsorptive state at 8 a.m. after a 12-14 h overnight fast. A polyethylene catheter was inserted into an antecubital vein for the infusion of glucose and insulin. Another catheter was inserted retrograde into a wrist vein for blood sampling. The hand was kept in a heated chamber at $70^{\circ} \mathrm{C}$ to allow arterialization of the venous blood (18).

At time zero, a first dose of $\left[3-{ }^{3} \mathrm{H}\right]$ glucose (New England Nuclear, Boston, MA) was rapidly injected (over 10-15 s) as a single bolus into another antecubital vein, and blood samples for tracer glucose determination were drawn from the arterialized venous line at $0.5 \mathrm{~min}$, then every $1 \mathrm{~min}$ until $15 \mathrm{~min}$, then at $17,19,21,23,25,28,31,34$, 37 , and $40 \mathrm{~min}$, and then every $10 \mathrm{~min}$ until $150 \mathrm{~min}$. At this time, a $1-\mathrm{mU} / \mathrm{min} \mathrm{kg}$ euglycemic insulin clamp (18) was begun, and continued for $180 \mathrm{~min}$. At time $240 \mathrm{~min}$ ( $90 \mathrm{~min}$ into the clamp), a second dose of $\left[3-{ }^{3} \mathrm{H}\right]$ glucose was again injected as a pulse via an antecubital vein, and arterialized blood was sampled at the same time intervals as after the first pulse of tracer for a total of $90 \mathrm{~min}$ (Fig. 1). Glucose kinetics were thus evaluated once in the fasting state, and a second time during steady-state euglycemic hyperinsulinemia. Since glucose clearance rate is slower in the fasting state than during insulin administration, the disappearance of the first bolus of tracer from plasma was followed for a longer time (150 min vs. $90 \mathrm{~min})$. For the same reason, a larger dose of tracer was given with the second than with the first bolus ( $94 \pm 2$ vs. $68 \pm 3 \mu \mathrm{Ci}$ ).

\section{Analytical procedures}

Plasma glucose was measured by the glucose oxidase method (on a Glucose Analyzer, Beckman Instruments, Inc., Fullerton, CA), and plasma insulin was determined by radioimmunoassay. Plasma $\left[{ }^{3} \mathrm{H}\right]$ glucose radioactivity was measured in duplicate on the supernatants of barium hydroxide-zinc sulphate precipitates (Somogyi's method) of plasma samples after evaporation to dryness to eliminate ${ }^{3} \mathrm{H}_{2} \mathrm{O}$. To determine the doses of the tracer accurately, three separate 1:100 dilutions of each injectate were run through the Somogyi procedure, and counted together with the plasma samples. The dose was then obtained as the product of the tracer concentration of the injectate by
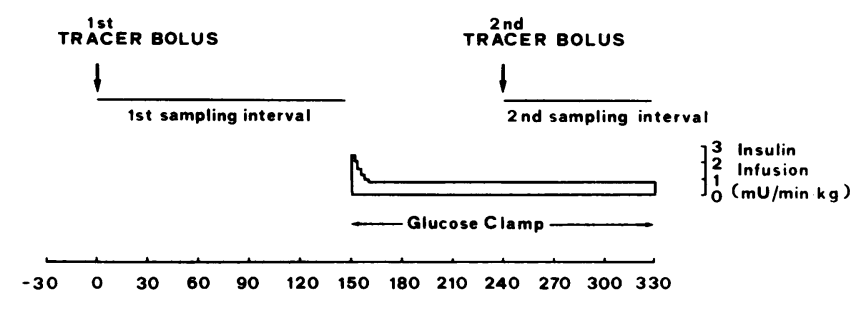

$$
\text { TIME (min) }
$$

Figure 1. Experimental protocol. the amount of injectate, which was determined by weight $(9.6 \pm 0.2$ and $13.4 \pm 0.3 \mathrm{~g}$, on the average, for the first and the second bolus, respectively).

\section{Data analysis}

Kinetic data description and measurement error. One-, two-, and threeexponential functions were fitted to the data of the two experiments. The errors inherent in the plasma labeled glucose measurements (which were done in duplicate) were assumed to be uncorrelated, and to have a Gaussian distribution of zero mean and an experimentally determined standard deviation. Representative figures for the coefficients of variation of the data were $2.3 \%$ at $8,000 \mathrm{cpm} / \mathrm{ml}$ and $6 \%$ at $500 \mathrm{cpm} / \mathrm{ml}$. A nonlinear least squares estimation technique was used to estimate the exponential parameters (23). The accuracy of parameter estimates was evaluated from the inverse of Fisher information matrix (24). Candidate analytical descriptions were compared on the basis of criteria such as residual errors, accuracy of parameter estimates, and Akaike Information Criterion (24). The three-exponential model proved to be superior under both basal and insulin-stimulated conditions (see reference 25 for details). In brief, the time-course of plasma radioactivity $(\mathrm{y}(t), \mathrm{cpm} /$ $\mathrm{ml}$ ) is described analytically as a sum of three exponentials:

$\mathrm{y}(t)=\mathrm{A}_{1} \mathrm{e}^{-\alpha_{1} t}+\mathrm{A}_{2} \mathrm{e}^{-\alpha_{2} t}+\mathrm{A}_{3} \mathrm{e}^{-\alpha_{3} t}$,

where $A_{1}, A_{2}$, and $A_{3}$ are the intercepts $(\mathrm{cpm} / \mathrm{ml})$ and $\alpha_{1}, \alpha_{2}$, and $\alpha_{3}$ are the slopes $\left(\mathrm{min}^{-1}\right)$ of the three exponential components.

From eq. 1, the initial distribution volume of glucose, $V_{1}(\mathrm{ml} / \mathrm{kg})$, is calculated as follows:

$V_{1}=\frac{\text { dose }}{A_{1}+A_{2}+A_{3}}$.

The plasma clearance rate of glucose, $\mathrm{PCR}^{1}(\mathrm{ml} / \mathrm{min} \mathrm{kg})$, is obtained from the following formula:

$$
\mathrm{PCR}=\frac{\text { dose }}{\frac{\mathrm{A}_{1}}{\alpha_{1}}+\frac{\mathrm{A}_{2}}{\alpha_{2}}+\frac{\mathrm{A}_{3}}{\alpha_{3}}} .
$$

Modeling strategy. Two linear modeling approaches were used to estimate the kinetic parameters of glucose distribution and disposition, namely the so-called noncompartmental and the compartmental approach (24). Only the salient features of the latter will be presented here. A more detailed description of the mathematical and computational aspects of the analysis can be found in (25).

Compartmental modeling requires the assumption of a specific model structure, its numerical identification, and subsequent validation $(24,26)$. Various linear compartmental models of glucose kinetics were examined. In particular, the two-compartment model structures proposed by Radziuk et al. (27) and by Atkins (28) were evaluated first, but were incompatible with our kinetic data (eq. 1). Threecompartment models fitted the tracer data best, and several possible configurations were explicitly evaluated (25). In the configuration eventually chosen (Fig. 2), endogenous glucose enters the system through the sampling compartment (compartment 1), and egresses both from a rapidly exchanging (compartment 2 ) and from a slowly exchanging compartment (compartment 3 ), the two loss paths ( $k_{02}$ and $\mathrm{k}_{03}$ ) being associated with insulin-independent and insulin-dependent glucose disposal, respectively. To reach unique identifiability of model parameters from experimental data, a constraint was imposed on the glucose loss from compartment 2 (see reference 25 and the appendix for details). Namely, this loss was assumed to equal a known amount $(\sim 75 \%)$ of the total glucose disposal rate in the fasting state, and its absolute value $(1.6 \pm 0.1 \mathrm{mg} / \mathrm{min} \mathrm{kg})$ was not allowed to change after insulin administration. The rationale for this choice is discussed later.

The unknown parameters (transfer rate constants, $k_{i j}$, and initial

1. Abbreviations used in this paper: $\mathrm{MRT}_{1}$, mean total residence time; PCR, plasma clearance rate; $V_{D}$, steady-state plasma-equivalent distribution volume of glucose. 


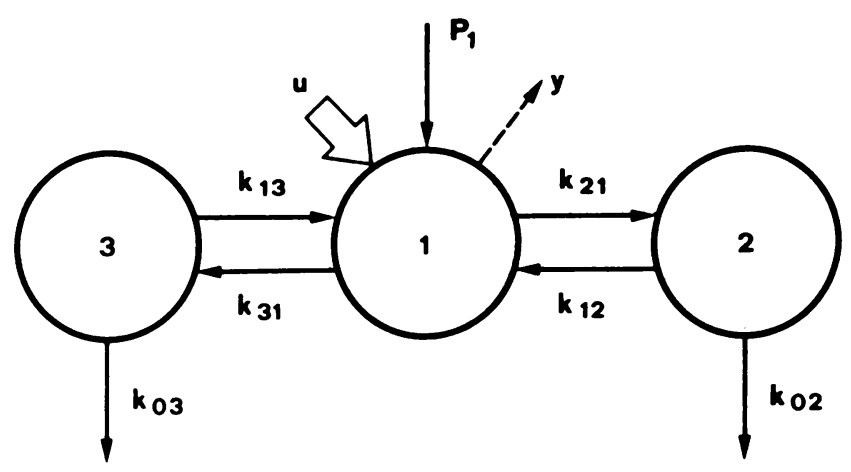

Figure 2. A three-compartment, mammillary model for the body glucose system. (1), Plasma; (2), rapidly equilibrating compartment (insulin-independent glucose utilization); (3), slowly equilibrating compartment (insulin-dependent glucose utilization).

distribution volume) were then estimated with the use of a nonlinear least squares estimation technique (29). The accuracy of parameter estimates was again obtained from the inverse of Fisher information matrix by solving the differential equation model and the associated sensitivity system simultaneously (24) (Table I). A number of other kinetic parameters were calculated from the compartment model. These include the mean total residence time $\left(\mathrm{MRT}_{1}\right)(\mathrm{min})$, the steadystate plasma-equivalent distribution volume $\left(V_{D}\right)(\mathrm{ml} / \mathrm{kg})$, and pool sizes $\mathrm{Q}_{1}, \mathrm{Q}_{2}$, and $\mathrm{Q}_{3}(\mathrm{mg} / \mathrm{kg})$.

Statistical analysis. Numerical values are presented as mean \pm SEM. The paired $t$ test was used to compare population means.

\section{Results}

Arterialized plasma glucose concentration was $88 \pm 3 \mathrm{mg} / 100$ $\mathrm{ml}$ in the fasting state, showed no change during the $150 \mathrm{~min}$ following the injection of the first bolus of tracer, and was clamped at $87 \pm 3 \mathrm{mg} / 100 \mathrm{ml}$ during the last $90 \mathrm{~min}$ of insulin infusion (Fig. 3). Fasting plasma insulin levels (14 $2 \mu \mathrm{U} / \mathrm{ml})$ also remained unchanged until $150 \mathrm{~min}$, when they were acutely raised, and maintained at $\sim 110 \mu \mathrm{U} / \mathrm{ml}$ throughout the study (Fig. 3). Exogenous glucose was infused at increasing rates to sustain euglycemia (Fig. 3). Over the last $90 \mathrm{~min}$ of the experiment, i.e., through the period of sampling of the second bolus of tritiated glucose, the glucose infusion rate rose from $7.63 \pm 0.60$ to $8.77 \pm 0.95 \mathrm{mg} / \mathrm{min} \mathrm{kg}$ (or by $15 \pm 10 \%, t$ $=1.51, P=\mathrm{NS})$. The effect of insulin on glucose kinetics, therefore, was assessed under conditions closely approaching the steady state.

Table I. Accuracy of Parameter Estimates with the Three-compartment Model*

\begin{tabular}{lcc}
\hline & Fasting & Insulin \\
\hline & $\%$ & $\%$ \\
$\mathrm{~V}_{1}(\mathrm{ml} / \mathrm{kg})$ & 7 & 6 \\
$\mathrm{~K}_{21}\left(\mathrm{~min}^{-1}\right)$ & 18 & 13 \\
$\mathrm{~K}_{12}\left(\min ^{-1}\right)$ & 8 & 12 \\
$\mathrm{~K}_{31}\left(\min ^{-1}\right)$ & 24 & 10 \\
$\mathrm{~K}_{13}\left(\min ^{-1}\right)$ & 17 & 26 \\
$\mathrm{~K}_{03}\left(\min ^{-1}\right)$ & 29 & 18 \\
\hline
\end{tabular}

* Values are mean (of six subjects) coefficients of variation of parameter estimates.
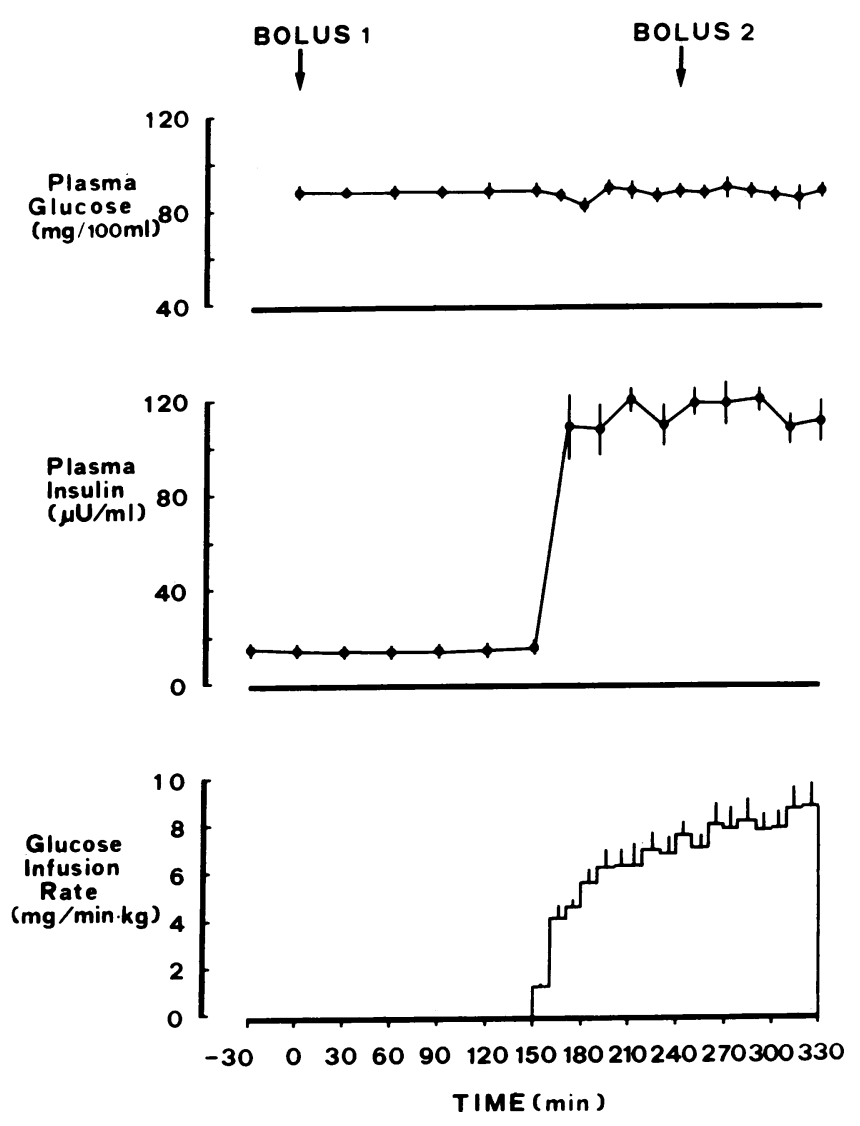

Figure 3. Plasma glucose (top) and insulin (middle) concentrations, and rates of exogenous glucose infusion (bottom) in six normal subjects in the basal state and during insulin administration $(1 \mathrm{mU} /$ min $\mathrm{kg}$, started at $150 \mathrm{~min}$ ).

The injected tracer glucose disappeared from plasma at a much faster rate during insulin administration than in the fasting state (Fig. 4). Three exponential terms fitted either set of isotopic data better than two exponentials (by least squares analysis). Both basally and after insulin, the time-activity curve was highly nonlinear (Fig. 5). The PCR of glucose was calculated to be $2.47 \pm 0.12 \mathrm{ml} / \mathrm{min} \mathrm{kg}$ in the fasting state, and $9.08 \pm 0.89$ $\mathrm{ml} / \mathrm{min} \mathrm{kg}$ during insulin infusion. The corresponding values for glucose disposal rate are $2.15 \pm 0.12$ and $7.96 \pm 0.85 \mathrm{mg} /$ min $\mathrm{kg}$. Since the total rate of glucose appearance calculated from the tracer data was not significantly different from the mean exogenous glucose infusion rate over the last $90 \mathrm{~min}$ of insulin infusion, endogenous glucose production must have been completely suppressed. The estimates of total glucose disposal derived from the clamp $(7.99 \pm 0.72 \mathrm{mg} / \mathrm{min} \mathrm{kg})$ and those obtained from the isotope data $(7.96 \pm 0.85 \mathrm{mg} / \mathrm{min} \mathrm{kg}$ ) correlated strongly with each other $(r=0.89, P<0.05)$.

The model. In the three-compartment model chosen (Fig. 2), new glucose (endogenous as well as exogenous) initially enters in the plasma, and subsequently distributes into two other body compartments. Since glucose is known not to be consumed in the plasma, no irreversible loss path was connected with this compartment. Glucose, however, was assumed to be irreversibly removed from both compartments 2 and 3 . It was further assumed that compartment 2 , which exchanges with the central (plasma) compartment more rapidly than does 


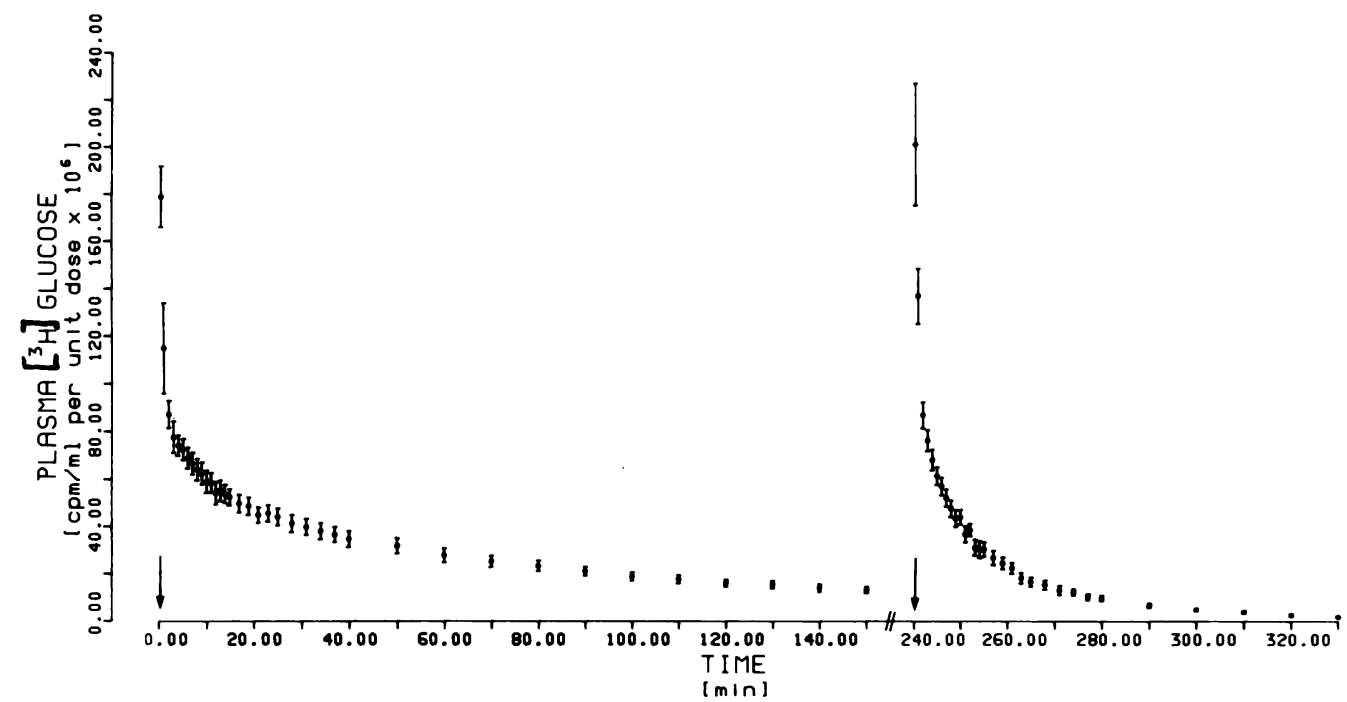

Figure 4. Plasma $\left[3-{ }^{3} \mathrm{H}\right] \mathrm{glucose}$ radioactivity in six normal subjects after bolus injection of the tracer in the basal state (left) and during a euglycemic insulin clamp (right). compartment 3, represents the insulin-independent tissues of the body (brain, splanchnic organs, formed elements of the blood, renal medulla). This insulin-independent glucose consumption was taken to be $75 \%$ of total glucose utilization in the basal state (i.e., $1.6 \pm 0.1 \mathrm{mg} / \mathrm{min} \mathrm{kg}$ ), and not to change under conditions of euglycemic hyperinsulinemia. The results of this modeling strategy are summarized in Fig. 6. In the fasting state, the glucose system occupied a total, plasmaequivalent space of $260 \pm 5 \mathrm{ml} / \mathrm{kg}$, containing a total of 227 $\mathrm{mg} / \mathrm{kg}$ of glucose on the average (or $16.5 \mathrm{~g}$ ). Of this amount, $40 \pm 3 \mathrm{mg} / \mathrm{kg}$ (or $2.8 \mathrm{~g}$ ) circulated in plasma, $91 \pm 12 \mathrm{mg} / \mathrm{kg}$ (or $6.5 \mathrm{~g}$ ) was in rapid exchange with plasma through compartment 2 , and $96 \pm 9 \mathrm{mg} / \mathrm{kg}$ (or $7.0 \mathrm{~g}$ ) was confined to the slowlyexchanging pool. The latter is the section of the system upon which hyperinsulinemia exerted its largest effects: twice as much glucose was transferred from pool 1 per unit time $(0.29 \pm 0.04 / \mathrm{min}, P<0.01$ vs. a basal rate of $0.12 \pm 0.01 / \mathrm{min})$, the pool size doubled (to $190 \pm 3 \mathrm{mg} / \mathrm{kg}$, or $13.7 \mathrm{~g}, P<0.02$ ), and the irreversible glucose loss rate rose about sixfold (to $0.035 \pm 0.003 / \mathrm{min}, P<0.001$ ) (Fig. 6). Except for a small (30\%), although statistically significant $(P<0.02)$, decrease in the size of the rapid compartment, neither the central pool nor the other exchange rate constants showed any change from the basal state. The effect of insulin on the $M_{R} T_{1}$ and $V_{\mathrm{D}}$ is shown in Fig. 7.

\section{Discussion}

In this study, the tracer-determined rates of glucose flux were not different from the rates of exogenous glucose infusion. Therefore, the tracer analysis correctly quantified the expected potency of insulin in inhibiting the release and stimulating the uptake of glucose $(15,30,31)$.

The use of modeling is inevitable if, in addition to fluxes, kinetic parameters are to be evaluated. Mathematical and statistical criteria can assist in the preliminary screening of

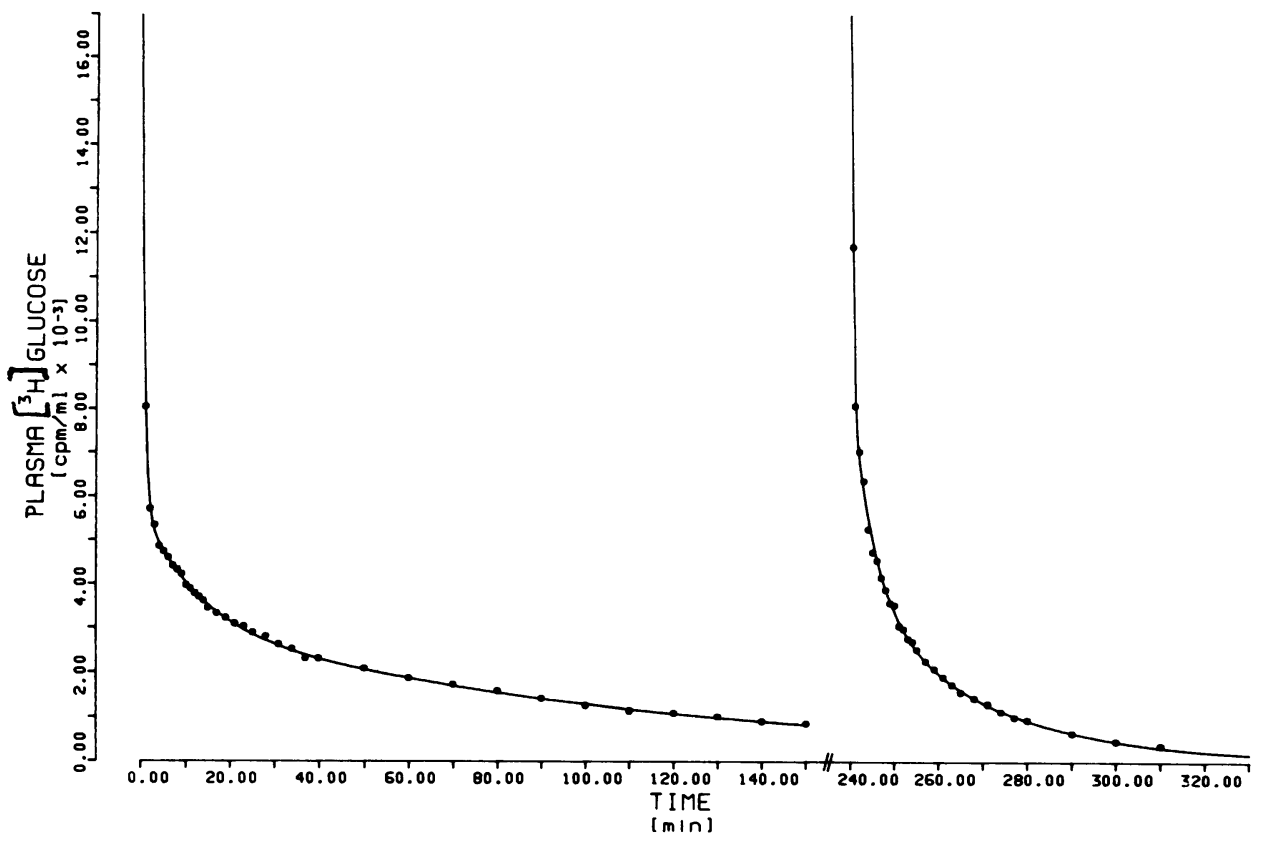

Figure 5. Experimental values (dots) and computer-generated fitting functions (solid lines) for plasma $\left[{ }^{3} \mathrm{H}\right]$ glucose concentrations in the basal state (left) and during insulin administration (right) in subject 3. 

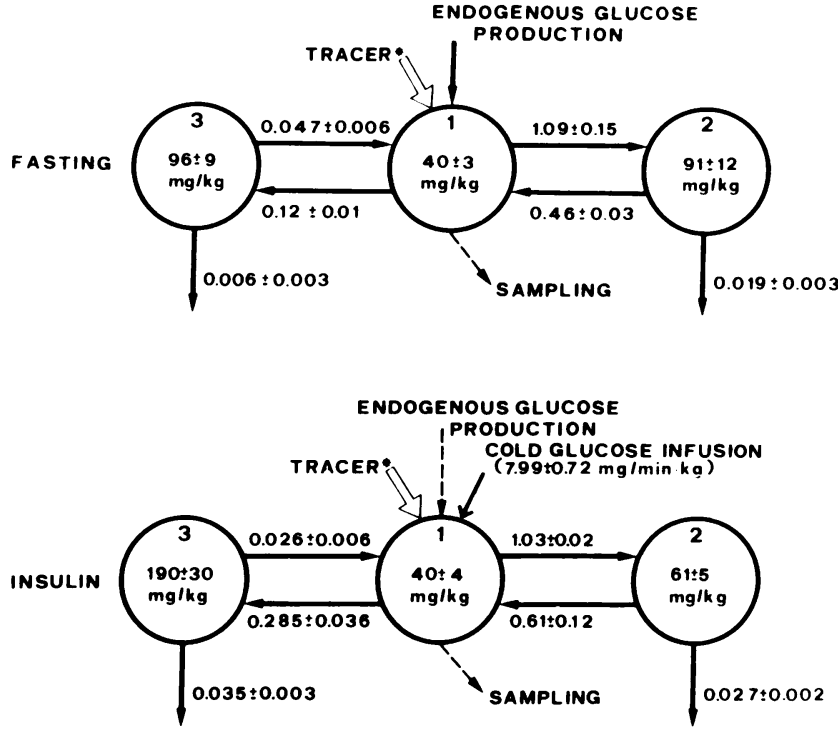

Figure 6. The three-compartment glucose model with the mean population values for masses and exchange constants in the basal state (top) and during steady-state euglycemic hyperinsulinemia (bottom). Rate constants are in units per minute; mean \pm SEM, $n=6$.

possible models. The ultimate selection, however, must rest upon the physiological compatibility and significance of the model. Our rather extensive trial of compartment models (25) showed that $(a)$ if sampled frequently enough, tracer glucose data can be satisfactorily incorporated into detailed physiological models; $(b)$ the use of only two compartments neglects the information carried by the initial downslope of the plasma tracer disappearance curve; $(c)$ of three compartments, the first (central) one is, by size, identifiable as the plasma volume quite closely; $(d)$ in addition to the central compartment, two other pools, a rapidly exchanging one and a slowly exchanging one, are evident in all the cases. Note that the noncompart-

BASAL INSULIN
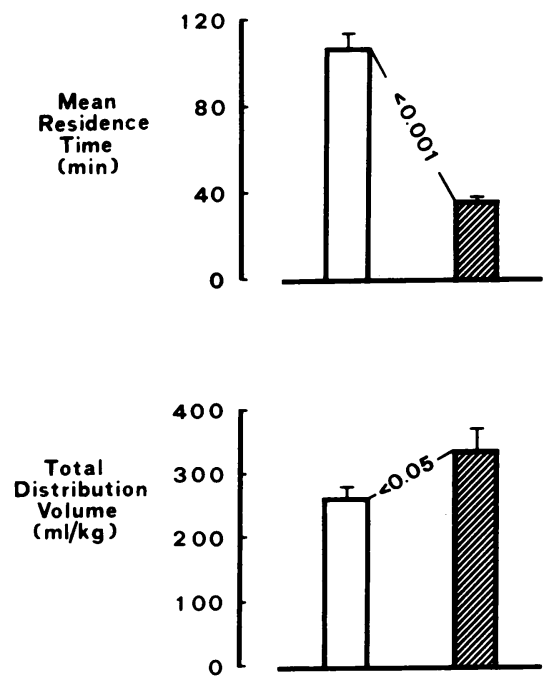

Figure 7. Mean residence time and total distribution volume of glucose in six normal subjects in the basal and insulinized state. Data calculated according to the model in Fig. 6. mental analysis, although theoretically compatible with the data $(1,32)$, is largely inadequate to describe glucose kinetics. In fact, the assumptions inherent in the noncompartmental approach, i.e., that glucose is directly utilized in the plasma or is removed by tissues that exchange so rapidly with plasma that they are kinetically indistinguishable from it, do not hold true.

In the resting, postabsorptive state, the brain, the splanchnic organs, and the kidneys collectively receive over $2 / 3$ of cardiac output, whereas skeletal and cardiac muscle account for $<20 \%$ of cardiac output (Table II). Per unit of tissue weight, blood flow to muscle and fat $(\sim 4 \mathrm{ml} / \mathrm{min}$ per $100 \mathrm{~g}$ of tissue) is much less than to the brain $(\sim 60 \mathrm{ml} / \mathrm{min} 100 \mathrm{~g})$ or the splanchnic organs $(\sim 100 \mathrm{ml} / \mathrm{min} 100 \mathrm{~g})$ or the heart $(100 \mathrm{ml} /$ min $100 \mathrm{~g})(33)$. Since the velocity of glucose transfer across capillary membranes is about 25 times greater than the linear blood flow in the vessel (33), the amount of glucose reaching the interstitia of the various tissues is only limited by the capillary surface area, i.e., by the blood flow per unit of tissue weight. Thus, the brain is exposed to about 15 times more glucose than the muscle per unit time. Glucose is readily taken up into cells of the cerebral, splanchnic, and renal tissues by facilitated diffusion; erythrocytes quickly equilibrate with plasma glucose (34). Therefore, it seems possible to assimilate these highly vascularized structures with a glucose kinetic compartment in rapid exchange with plasma. The cumulative glucose disposal by these tissues in the basal state can be estimated at $1.5-1.7 \mathrm{mg} / \mathrm{min} \mathrm{kg}$ (Table II and Fig. 6). Insulin does not stimulate glucose uptake by the splanchnic organs (15), erythrocytes (34), or the renal medulla (35). The effect of the hormone on brain glucose uptake is still somewhat controversial (36-39), but the weight of the evidence seems to favor the concept that cerebral glucose utilization is insulin-independent. Consequently, the rapid compartment can be further identified as an insulin-independent pool. Under conditions of constant glycemia, any effect of hyperinsulinemia must then be exerted on the slow compartment. In other words, any model having only central (plasma) loss paths (e.g., the noncompartmental model) is insufficient to account for known patterns of plasma glucose disposition. On the other hand, a three-compartment model featuring insulin-independent and insulin-dependent glucose losses is compatible with tracer kinetic data and

Table II. Summary of Blood Flow and Glucose Uptake Rates by Intact Organs of Human in the Basal, Postabsorptive State*

\begin{tabular}{ccccc} 
Blood flow & Blood flow & $\begin{array}{l}\text { Glucose } \\
\text { uptake }\end{array}$ & $\begin{array}{l}\text { Glucose } \\
\text { uptake }\end{array}$ \\
\hline $\mathrm{ml} / \mathrm{min} \mathrm{kg}$ & $\begin{array}{l}\text { \% of cardiac } \\
\text { output }\end{array}$ & $\mathrm{mg} / \mathrm{min} \mathrm{kg}$ & \% of total
\end{tabular}

Brain (46)

Splanchnic organs (15)

Kidneys (35)

Muscle $(47,48)$

Heart (49)

Erythrocytes (34)

Other

Total

12
21
16
13
2
-
16

80

15
26
20
16
3
-
20

100

$$
\begin{gathered}
1.2 \\
0.5 \\
<0.1 \\
0.3 \\
0.09 \\
0.06 \\
<0.01
\end{gathered}
$$

2.2

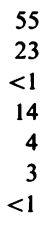

100
* The numbers in parenthesis indicate the source reference. Rates are per kilogram of body weight. Average, rounded-off values are given. 
incorporates current notions on the circulatory dynamics and modes of glucose disposition in the various tissues of the body.

Insel et al. (12) also developed a kinetic model for glucose having three compartments with a parallel connection. Like us, these authors featured two modes of glucose loss, one insulin-independent (or of zero order), the other insulindependent. Our results, however, differ from those of the study of Insel et al. in several respects. First, their rates of glucose production in the fasting state averaged $1.7 \mathrm{mg} / \mathrm{min} \mathrm{kg}$, and were incompletely suppressed (70\%) during a $1-\mathrm{mU} / \mathrm{min} \mathrm{kg}$ euglycemic insulin clamp. We and others $(15,30,31,40)$, on the contrary, find higher values for basal endogenous glucose release $(2.0-2.4 \mathrm{mg} / \mathrm{min} \mathrm{kg}$ ), and complete inhibition by insulin levels comparable to those achieved in that study. This discrepancy could be explained by their using $\left[{ }^{14} \mathrm{C}\right]$ glucose as the tracer. Although a correction for recycling of tracer glucose was applied, the choice of the isotope remains a potential source of difference. Second, their data were inadequate to define the initial space of distribution of glucose, which therefore had to be assumed. In the present experiments, we sampled the early time period very frequently, the first blood sample being obtained $30 \mathrm{~s}$ after the beginning of tracer injection. This design, coupled with precise determination of plasma glucose radioactivity, made it possible to identify the initial distribution volume of glucose in every subject quite confidently, both before and after insulin administration. Third, the values for $V_{\mathrm{D}}$ in the basal state obtained in this and many other studies $(3,4,9,40)$ are higher $(25 \%$ vs. $20 \%$ of body wt) than those reported by Insel et al., regardless of the computational method. Finally, in Insel's study (as in ours) it was anticipated that insulin would control glucose transport from the slowly exchanging, insulin-independent glucose compartment; however, in subjects displaying a large insulin effect, the tracer data were incompatible with a rapid enough supply of glucose to this compartment. Our slow pool exchanged with plasma significantly more rapidly than Insel's slow pool already in the basal state $\left(0.12 \pm 0.01\right.$ vs. $\left.0.07 \pm 0.02 \mathrm{~min}^{-1}\right)$ and in no case did it restrain glucose arrival to this compartment during insulin infusion.

Having thus determined a likely structure for the glucose system (Fig. 6), the major finding of this study was the effect of insulin on overall glucose kinetics. In addition to the expected stimulation of total glucose uptake, insulin administration brought about a significant increase in the size of the total distribution volume of glucose, which was confined to its slowly-exchanging, insulin-sensitive section. On theoretical grounds, this finding has three potential explanations. $(a)$ The physical space of glucose distribution is truly expanded, and glucose is contained in this pool at the same concentration as in plasma. This event is, however, highly unlikely, because it would entail an actual weight gain of $5 \mathrm{~kg}$ in a $70-\mathrm{kg}$ man, or the transfer of five liters of fluid from the intracellular to the extracellular compartment. Quite to the contrary, during a euglycemic insulin clamp the water balance is only slightly positive (DeFronzo et al., unpublished observations), and sodium and potassium are driven into the cells (42). (b) The size of the slowly-exchanging compartment is unchanged but glucose is here contained at twice the concentration of plasma glucose. Although this possibility cannot be ruled out, it is difficult to envision how a concentration gradient between the interstitium of muscle and the plasma would be created and maintained in the absence of changes in blood flow, venous return, or lymphatic drainage. (c) The intracellular space becomes accessible to glucose, and part of the intracellular water exchanges with extracellular glucose. Insulin has long been known to increase the volume of distribution of several hexoses and pentoses in the body water by accelerating their transfer into cells (1). Intracellular free glucose concentrations are normally close to zero and glucose transport is rate-limiting for glucose utilization. Insulin enhances glucose transport into diaphragm, heart, and skeletal muscle, but not into brain, in the rat (43) and the dog (44) without altering the volume of the extracellular water. When glucose transport is stimulated strongly, phosphorylation becomes the rate-limiting step in glucose metabolism, and free glucose builds up in the cell (45). This free glucose can flow back out of cells, thereby contributing to what is measured as the exchangeable glucose pool in kinetic experiments. Several lines of evidence support this interpretation. Direct measurements of leg glucose uptake during a $1-\mathrm{mU} / \mathrm{min} \mathrm{kg}$ insulin clamp have made it possible to calculate that $85 \%$ of the infused glucose is taken up by muscle (15). In the present analysis, glucose loss from the slow compartment amounted to $83 \%$ of total glucose loss during insulin administration. In addition, only the slow glucose pool was expanded in the insulinized state, whereas the size of the rapid pool was not much affected, as would be predicted for insulin-insensitive glucose pathways. Finally, a strong correlation was found between glucose removal and the increase of the slow pool itself ( $r=0.92, P<0.01$, Fig. 8 ), suggesting that this effect of insulin on glucose distribution is rate-dependent, and may become detectable only at high $(>6 \mathrm{mg} / \mathrm{min} \mathrm{kg})$ rates of glucose disposal. Note that, if the insulin-mediated glucose uptake is assumed to move from the rapid compartment instead of the slow pool, insulin still enhances glucose removal 10 -fold, but fails to affect the pool size $(77 \pm 10$ vs. $86 \pm 8 \mathrm{mg} /$ $\mathrm{kg}$, data not shown).

In summary, when both kinetic and physiologic information is used, it is possible to develop a minimum-assumption compartmental model for the glucose system. When tested under controlled conditions of hyperinsulinemia, the model indicates significant changes in the size of the insulin-sensitive pool, probably due to the accumulation of free glucose in the intracellular water of muscle tissue. There are important

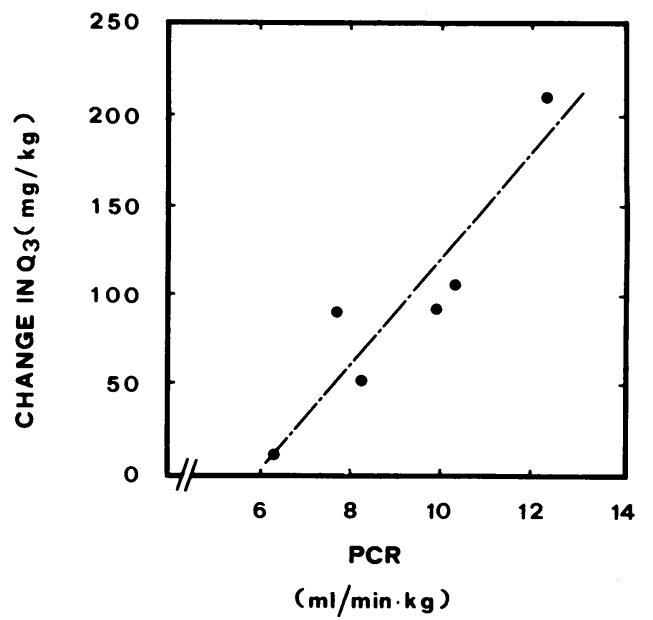

Figure 8. Relationship between the change in the slow pool size ( 3 in Fig. 6) from the basal to the insulinized state and total glucose disposal. $y=-170+29 \mathrm{x} ; r=0.92 ; P<0.01$. 
implications of this analysis. First, turnover calculations in the nonsteady state cannot be based simply on the assumption that the glucose system is invariant with respect to size and exchange rates (41). More experimentation is needed to establish the kinetic behavior of the glucose system under conditions encountered in normal and disease states. For instance, the effect of hyperglycemia on glucose kinetics should be studied, together with its implications for the diabetic state. Secondly, glucose disappearance from plasma should not be invariably thought of as glucose utilization. Our analysis suggests that, at high rates of transport, some of the glucose removed from the circulation may not be immediately metabolized, but may be sequestered as such within the cells to be utilized at later times. By taking the current average figures, it can be calculated that roughly $90 \mathrm{mg} / \mathrm{kg}$ of glucose accumulated in the slow pool between the two measurements of the $V_{D}$ of glucose; from this it follows that $14 \%$ of the exogenous glucose required to maintain euglycemia is not to be accounted for by either glycogen deposition or glucose breakdown, and should be excluded from energy balance calculations.

\section{Appendix}

The identifiability analysis yields for the model and tracer experiment of Fig. 2 the following transfer function (24):

$\mathrm{H}_{11}(\mathbf{s})=\frac{\beta_{3} \mathrm{~s}^{2}+\beta_{2} \mathrm{~s}+\beta_{1}}{\mathrm{~s}^{3}+\alpha_{3} \mathrm{~s}^{2}+\alpha_{2} \mathrm{~s}+\alpha_{1}}$,

where $\beta_{1}, \beta_{2}, \beta_{3}, \alpha_{1}, \alpha_{2}$, and $\alpha_{3}$ are known constants.

Six equations are therefore available to solve for the six transfer rate parameters $\mathrm{k}_{\mathrm{ij}}$ and the initial distribution volume $V_{1}$. These equations $(24$, p. 136$)$ show that the model is not identifiable. The following parameter combinations, however, are uniquely identifiable once compartments 2 and 3 have been chosen as the fast and slow pool, respectively:

$$
\begin{aligned}
V_{1} & =1 / \beta_{3} \\
-\left(\mathrm{k}_{21}+\mathrm{k}_{31}\right) & =-\alpha_{3}+\beta_{2} / \beta_{3}=\mathrm{k}_{11} \\
-\left(\mathrm{k}_{02}+\mathrm{k}_{12}\right) & =\frac{-\beta_{2} / \beta_{3}-\sqrt{\left(\beta_{2} / \beta_{3}\right)^{2}-4 \beta_{1} / \beta_{3}}}{2}=\mathbf{k}_{22} \\
-\left(\mathrm{k}_{03}+\mathrm{k}_{13}\right) & =\frac{-\beta_{2} / \beta_{3}+\sqrt{\left(\beta_{2} / \beta_{3}\right)^{2}-4 \beta_{1} / \beta_{3}}}{2}=\mathrm{k}_{33} \\
\mathrm{k}_{12} \mathrm{k}_{21} & =\frac{\mathrm{k}_{22}^{2}\left(\mathrm{k}_{11}+\mathrm{k}_{33}\right)-\alpha_{2} \mathrm{k}_{22}-\alpha_{1}}{\mathrm{k}_{22}-\mathrm{k}_{33}}=\gamma \\
\mathrm{k}_{13} \mathrm{k}_{31} & =\frac{-\mathrm{k}_{33}^{2}\left(\mathrm{k}_{11}+\mathrm{k}_{22}\right)+\alpha_{2} \mathrm{k}_{33}+\alpha_{1}}{\mathrm{k}_{22}-\mathrm{k}_{33}}=\delta .
\end{aligned}
$$

The six equations 2-7 are independent in the seven unknown parameters. To reach unique identifiability of the parameters another independent equation must be considered. Here an a priori constraint was imposed on the glucose loss from compartment 2 (insulinindependent utilization), which was assumed to be known:

$\mathrm{k}_{02} \mathrm{Q}_{2}=\mathrm{U}_{2}^{\prime}$,

where $Q_{2}$ is glucose mass in compartment 2 and $U_{2}^{\prime}$ is a given constant.

As $Q_{2}$ from tracee steady-state equations is given by

$\mathrm{Q}_{2}=\frac{\mathrm{k}_{12}}{-\mathrm{k}_{22}} \mathrm{Q}_{1}=\frac{\mathrm{k}_{12}}{-\mathrm{k}_{22}} V_{1} \cdot \mathrm{c}$,

where $Q_{1}$ is glucose mass in compartment 1 and $c$ is steady-state plasma glucose concentration, the constraint provides $\frac{\mathrm{k}_{21} \mathrm{k}_{02}}{-\mathrm{k}_{22}} V_{1}=\mathrm{U}_{2}^{\prime} / \mathrm{c}=\mathrm{U}_{2}$,

where $\mathrm{U}_{2}$ is a constant.

Unique identifiability of $\mathrm{k}_{\mathrm{ij}}$ and $V_{1}$ is now reached from eq.'s 2-7 and 10.

Eq. 2 provides $V_{1}$.

From eq. 6 and $10 k_{21}$ is provided:

$\mathrm{k}_{21}=\frac{\mathrm{U}_{2}}{V_{1}}-\frac{\gamma}{\mathrm{k}_{22}}$,

and thus from eq. 6 ,

$\mathbf{k}_{12}=\gamma / \mathbf{k}_{21}$.

Now from eq. $4 \mathrm{k}_{02}$ is provided:

$\mathbf{k}_{02}=-\mathbf{k}_{22}-\mathbf{k}_{12}$.

Parameter $k_{31}$ is determined from eq. 3:

$k_{31}=-k_{11}-k_{21}$,

and thus from eq. 7 we have:

$\mathbf{k}_{13}=\delta / \mathbf{k}_{31}$.

Finally, from eq. 5 we have:

$\mathbf{k}_{03}=-\mathbf{k}_{33}-\mathbf{k}_{13}$.

\section{Acknowledgments}

We are indebted to Daniela Banti for typing the manuscript.

This work was supported in part by National Institutes of Health grants AM-20495, AM-24092, and RR-125, by Public Health Service International Research Fellowship 1-F05-TW02716-01, and by a grant from the Italian Ministry of Public Education.

\section{References}

1. Park, C. R., L. H. Johnson, J. H. Wright, Jr., and H. Batsel. 1957. Effect of insulin on transport of several hexoses and pentoses into cells of muscle and brain. Am. J. Physiol. 191:13-18.

2. Distefano, J. J., III. 1982. Noncompartmental vs. compartmental analysis: some bases for choice. Am. J. Physiol. 243:R1-6.

3. de Bodo, R. C., R. Steele, N. Altszuler, A. Dunn, and J. S. Bishop. 1963. On the hormonal regulation of carbohydrate metabolism. Studies with $C^{14}$ glucose. Recent Prog. Horm. Res. 19:445-482.

4. Searle, G. C., G. E. Mortimore, R. E. Buckley, and W. A. Reilly, 1959. Plasma glucose turnover in humans as studied with $C^{14}$ glucose. Influence of insulin and tolbutamide. Diabetes. 8:163-173.

5. Hetenyi, G. J., G. A. Wrenshall, and C. H. Best. 1961. Rates of production, utilization, accumulation and apparent distribution spaces of glucose. Diabetes. 10:304-311.

6. Atkins, G. L. 1971. Investigation of some theoretical models relating the concentration of glucose and insulin in plasma. $J$. Theor. Biol. 32:471-494.

7. Norwich, K. H. 1969. Mathematical models of the kinetics of glucose and insulin in plasma. Bull. Math. Biophys. 31:105-121.

8. Segal, S., M. Berman, and A. Blair. 1961. The metabolism of $\mathrm{C}^{14}$-labeled glucose in man and an estimation of the extent of glucose metabolism by the hexose monophosphate pathway. J. Clin. Invest. 40:1263-1279.

9. Gatewood, L. C., E. Ackerman, J. W. Rosevear, and G. D. Molnar. 1970. Modelling blood glucose dynamics. Behav. Sci. 15: 72-87.

10. Baker, N., R. A. Shipley, R. E. Clark, and G. E. Incefy. 1959. $\mathrm{C}^{14}$ studies in carbohydrate metabolism: glucose pool size and rate of turnover in the normal rat. Am. J. Physiol. 196:245-252.

11. Kronfeld, D. S., C. F. Ramberg, Jr., and D. M. Shames. 1971. 
Multicompartmental analysis of glucose kinetics in normal and hypoglycemic cows. Am. J. Physiol. 220:886-893.

12. Insel, P. A., J. E. Liljenquist, J. D. Tobin, R. S. Sherwin, P. Watkins, R. Andres, and M. Berman. 1975. Insulin control of glucose metabolism in man. J. Clin. Invest. 55:1057-1066.

13. Bjorntorp, P., and L. Sjostrom. 1978. Carbohydrate storage in man. Speculations and some quantitative considerations. Metabolism. 27(Suppl. 2):1853-1863.

14. DeFronzo, R. A., E. Ferrannini, R. Hendler, J. Wahren, and P. Felig. 1978. Influence of hyperinsulinemia, hyperglycemia, and route of glucose administration on splanchnic glucose exchange. Proc. Natl. Acad. Sci. USA. 75:5173-5177.

15. DeFronzo, R. A., E. Jacot, E. Jequier, E. Maeder, J. Wahren, and J. P. Felber. 1981. The effect of insulin on the disposal of intravenous glucose. Results from indirect calorimetry and hepatic and femoral venous catheterization. Diabetes. 30:1000-1007.

16. DeFronzo, R. A., E. Ferrannini, R. Hendler, P. Felig, and J. Wahren. 1983. Regulation of splanchnic and peripheral glucose uptake by insulin and hyperglycemia in man. Diabetes. 32:35-45.

17. Radziuk, J., and R. Inculet. 1983. The effects of ingested and intravenous glucose on forearm uptake of glucose and glucogenic substrate in normal man. Diabetes. 32:977-981.

18. DeFronzo, R. A., J. D. Tobin, and R. Andres. 1979. Glucose clamp technique: a method for quantifying insulin secretion and resistance. Am. J. Physiol. 237:E214-E223.

19. Katz, J., and A. Dunn. 1967. Glucose-2-T as a tracer for glucose metabolism. Biochemistry. 6:1-5.

20. Katz, J., A. Dunn, M. Chenoweth, and S. Golden. 1974. (a) Determination of synthesis, recycling and body mass of glucose in rats and rabbits in vivo with ${ }^{3} \mathrm{H}$ - and $\mathrm{C}^{14}$-labelled glucose. Biochem. J. 142: 171-183.

21. Issekutz, B., Jr., M. Allen, and I. Borkow. 1972. Estimation of glucose turnover in the dog with glucose-2-T and glucose-U-14C. Am. J. Physiol. 222:710-712.

22. Issekutz, T. B., B. Issekutz, Jr., and D. Elahi. 1974. Estimation of hepatic glucose output in non-steady state. The simultaneous use of $2-{ }^{3} \mathrm{H}$-glucose and ${ }^{14} \mathrm{C}$-glucose in the dog. Can. J. Physiol. Pharmacol. 52:215-224.

23. Harwell Subroutine Library, VC04A. 1972. Her Majesty's Stationery Office, London.

24. Carson, E. R., C. Cobelli, and L. Finkelstein. 1983. Mathematical modeling of metabolic and endocrine systems. Model Formulation, Identification and Validation. John Wiley, New York.

25. Cobelli, C., G. Toffolo, and E. Ferrannini. 1984. A model of glucose kinetics and their control by insulin. Compartmental and noncompartmental approaches. Math. Biosci. 72:291-316.

26. Rescigno, A., and E. Gurpide. 1973. Estimation of average times of residence, recycle and interconversion of blood-borne compounds using tracer methods. J. Clin. Endocrinol. Metab. 36:263-276.

27. Radziuk, J., K. H. Norwich, and M. Vranic. 1978. Experimental validation of measurements of glucose turnover in non-steady state. Am. J. Physiol. 234:E84-E93.

28. Atkins, G. L. 1980. A new technique for maintaining and monitoring conscious, stress-free rabbits in a steady state: its use in the determination of glucose kinetics. Q. J. Exp. Physiol. Cogn. Med. Sci. 65:63-75.

29. Fletcher, R. 1971. A modified Marquardt subroutine for nonlinear least squares. In Atomic Research Establishment. Report $\mathbf{R}$ AERE-R 6799. Her Majesty's Stationery Office, London.

30. Kolterman, O. G., J. Insel, M. Saekow, and J. M. Olefsky. 1980. Mechanisms of insulin resistance in human obesity. Evidence for receptor and postreceptor defects. J. Clin. Invest. 65:1272-1284.
31. Rizza, R. A., L. J. Mandarino, and J. E. Gerich. 1981. Doseresponse characteristics for effects of insulin on production and utilization of glucose in man. Am. J. Physiol. 240:E630-E639.

32. Cobelli, C., and G. Toffolo. 1984. Compartmental vs. noncompartmental modeling for two accessible pools. Am. J. Physiol. 247: R488-R496.

33. Guyton, A. C. 1971. Textbook of Medical Physiology. W. B. Saunders Company, Philadelphia, PA. Fourth ed. 359-378.

34. Murphy, J. R. 1960. Erythrocyte metabolism. The equilibration of glucose- $\mathrm{C}^{14}$ between serum and erythrocytes. J. Lab. Clin. Med. 55: 281-302.

35. Lee, J. B., V. K. Vance, and G. F. Cahill. 1962. Metabolism of $\mathrm{C}^{14}$-labeled substrates by rabbit kidney cortex and medulla. Am. J. Physiol. 203:27-36.

36. Reinmuth, O. M., P. Scheinberg, and B. Bourne. 1965. Total cerebral blood flow and metabolism. Arch. Neurol. 12:49-66.

37. Scheinberg, P. 1965. Observations on cerebral carbohydrate metabolism in man. Ann. Intern. Med. 62:367-371.

38. Owen, O. E., A. P. Morgan, H. G. Kemp, J. M. Sullivan, M. G. Herrera, and G. F. Cahill. 1967. Brain metabolism during fasting. J. Clin. Invest. 46:1589-1595.

39. Ahlborg, G., and J. Wahren. 1972. Brain substrate utilization during prolonged exercise. Scand. J. Clin. Lab. Invest. 29:397-402.

40. Tserng, K., and S. C. Kalhan. 1983. Estimation of glucose carbon recycling and glucose turnover with $\mathrm{U}-{ }^{13} \mathrm{C}$-glucose. $\mathrm{Am} . \mathrm{J}$. Physiol. 245:E476-E482.

41. Cobelli, C., A. Ruggeri, G. Toffolo, A. Avogaro, and R. Nosadini. 1983. Is the "pool-fraction" paradigm a valid model for assessment of in vivo turnover in non-steady state? Am. J. Physiol. 245:R624-R632.

42. DeFronzo, R. A., C. R. Cooke, R. Andres, G. R. Faloona, and P. J. Davis. 1975. The effect of insulin on renal handling of sodium, potassium, calcium, and phosphate in man. J. Clin. Invest. 55:845855.

43. Park, C. R., and L. H. Johnson. 1975. Effect of insulin on transport of glucose and galactose into cells of rat muscle and brain. Am. J. Physiol. 182:17-26.

44. Levine, R., M. S. Goldstein, B. Huddlestun, and S. Klein. 1950. Action of insulin on the "permeability" of cells to free hexoses, as studied by its effects on the distribution of galactose. Am. J. Physiol. 163:70-81.

45. Park, C. R., D. Reinwein, M. J. Henderson, E. Cadenas, and H. E. Morgan. 1959. The action of insulin on the transport of glucose through the cell membrane. Am. J. Med. 26:674-684.

46. Scheinberg, P., and E. A. Stead, Jr. 1949. The cerebral blood flow in male subjects as measured by the nitrous oxide technique. Normal values for blood flow, oxygen utilization, glucose utilization, and peripheral resistance, with observations on the effect of tilting and anxiety. J. Clin. Invest. 28:1163-1171.

47. Andres, R., G. Cader, and K. L. Zierler. 1956. The quantitatively minor role of carbohydrate in oxidative metabolism by skeletal muscle in intact man in the basal state. Measurements of oxygen and glucose uptake and carbon dioxide and lactate production in the forearm. J. Clin. Invest. 35:671-682.

48. Rabinowitz, D., and K. L. Zierler. 1962. Forearm metabolism in obesity and its response to intra-arterial insulin. Characterization of insulin resistance and evidence for adaptive hyperinsulinemia. J. Clin. Invest. 41:2173-2181.

49. Neely, J. R., and H. E. Morgan. 1974. Relationship between carbohydrate and lipid metabolism and energy balance of heart muscle. Ann. Rev. Physiol. 36:413-440. 